\title{
Mujeres trágicas en el cine latinoamericano contemporáneo
}

\author{
Tragic women in contemporary Latin American cinema
}

\author{
Lia Sabrina Noguera liasabrinanoguera@gmail.com \\ https://orcid.org/0000-0002-0765-5160 \\ Universidad Nacional de Buenos Aires/ Universidad Nacional de las Artes (Argentina)
}

\section{Resumen}

En el presente artículo nos proponemos analizar la productividad de la tragedia en el cine latinoamericano contemporáneo, a partir de la Medea de Eurípides y Séneca. Nos interesa estudiar, a través del concepto de profanación (Agamben), los nuevos modos de representación de la poética trágica, sus funciones y resignificaciones como así también la representación que los filmes Así es la vida (2000) y Medea (2017) proponen en relación con la mujer y la maternidad en las sociedades latinoamericanas contemporáneas. 
Palabras clave: Tragedia; cine mexicano; cine costarricense; mujer; maternidad.

\begin{abstract}
In this article we propose to analyze the productivity of the tragedy, starting with Medea by Euripides and Séneca, in contemporary Latin American cinema. We are interested in studying, through the concept of profanation (Agamben), the new ways of representation of tragic poetic, their functions and resignifications as well as the representation that the films Así es la vida and Medea propose in relation to women and maternity in contemporary Latin American societies.
\end{abstract}

Key words: Tragedy; mexican cinema; costa rican cinema; woman; maternity.

La productividad del intertexto trágico, tanto en el teatro como en el cine es innegable. Las formas en las que diferentes dramaturgos y cineastas se han apropiado de la textualidad helénica produciendo nuevas texturas significantes y arrojando así otras maneras de ver los conflictos originarios presentes en tal mitología con el fin de actualizarlas y hacerlas hablar de nuestras propias cotidianeidades y de nuestras propias coyunturas político y sociales es otro hecho que tampoco es cuestionado. Porque el ideario helénico ha seducido a lo largo de la historia y ha provocado nuevas escrituras que permiten entrever un horizonte diferente, a la vez que contemporáneo, sobre nuestras propias configuraciones intelectuales, generando así un modo de identificación entre esos sujetos trágicos, en el caso de la tragedia ática, que permiten rehistorizar nuestro pasado y pensar nuestro presente. Porque, y tal como lo señala Bauzá:

\footnotetext{
La tragedia griega nos advierte que la sociedad no es un habeas homogéneo del que todos participan de manera armoniosa (...) es una suerte de revés de la trama del orden social, toda vez que pone de manifiesto las tensiones -muchas veces agónicas- que subyacen en el interior de esa urdiembre cívica (2002: 312).
}

Asimismo, la tragedia es considerada un instrumento conceptual útil para pensar la política a partir de una característica nodal que la constituye: el conflicto. Pero si en la tragedia, la característica de ese conflicto reside en la incapacidad de resolverse, "de canalizarse a través de instituciones que permitan que su resultado no sea una catástrofe", como afirma Eduardo Rinesi (2015: 3), por el contario, la naturaleza del conflicto en la política parte del supuesto de 
que él pueda procesarse y resolverse por medio de las instituciones a fin de evitar "caer del otro lado del precipicio".

Ahora bien, si el teatro griego erigió sus conflictos en torno a la oposición entre hombres y dioses, como en el caso de Antígona de Sóflocles y la tragedia renacentista y moderna los cimentó en el interior mismo de los sujetos, encontramos que un texto como Medea se encabalga entre estas dos conflictividades. Por tal motivo, nos interesa volver sobre los pasos de estas mujeres, pero sobre todo, sobre el modo en el cual su conflicto es retomado y resemantizado por el cine contemporáneo latinoamericano. Para ello, creemos fundamental entender que las transposiciones, como así también las reescrituras que de este mito se realizan en el cine y el teatro (como así también de otros mitos), surgen a partir de la profanación de las estructuras características de la tragedia permitiendo así habilitar nuevos usos y significaciones. Pero ahora bien, ¿qué entendemos por profanación?

Girogio Agamben (2013) en su artículo "Elogio de la profanación" establece una distinción entre lo sagrado y lo profano. Si lo primero es considerado aquello que se extrae del uso cotidiano y, mediante la consagración, se entregaba a los dioses; lo segundo es aquello que, a través del uso, se extrae del orden de los dioses y se restituye al derecho de los hombres. Señala también, que una forma posible de lo profano es mediante el juego puesto que libera y aleja del orden de lo sagrado. Asimismo, advierte una distinción entre la secularización y la profanación que si bien reconoce como operaciones políticas, dice que "la primera tiene que ver con el ejercicio del poder, garantizándolo mediante la referencia a lo sagrado; la segunda desarticula los dispositivos del poder y restituye al uso común los espacios que el poder había confiscado." (Agamben, 2013: 102). Sin embargo, él considera que en la actualidad la profanación se volvió un improfanable puesto que la posibilidad de usar se canceló con la maquinaria museística a la cual iguala con la lógica del capitalismo. En el museo todo se congela y la posibilidad de generar experiencia se agota produciendo así sólo transeúntes que observan y acumulan imágenes y discursos sin capacidad de generar nuevas experiencias. Así, y en palabras de Agamben:

\footnotetext{
El museo hoy ocupa exactamente el espacio y la función que antes cumplía el templo. (...) Si los cristianos eran peregrinos (extranjeros en la tierra porque su patria era el cielo), los adeptos del nuevo culto capitalista no tienen patria alguna porque viven en la pura forma de separación. Donde quieran que vayan, ellos encuentran multiplicada y llevada al extremo la misma posibilidad de habitar que habían conocido en sus casas y en sus ciudades, la misma incapacidad de usar que habían experimentado en los supermercados, en los shoppings y en los espectáculos televisivos (2013: 110).
} 
A pesar de este panorama desolador que expone Agamben, él otorga una luz en ese camino y sugiere que aún hay formas de profanar lo improfanable. Esto es mediante la desactivación de un viejo uso para volverlo inoperante y mediante esa manera producir nuevos usos. Son estas ideas sobre la profanación las que nos interesa retomar para reflexionar sobre las transposiciones que el cine latinoamericano hace de las tragedias, y en especial para este artículo nos concentraremos en Antígona de Sófocles y Medea de Eurípides y Séneca. Para ello, analizaremos los grados de profanación que el cine mexicano y costarricense -a partir de los filmes Así es la vida (2000) y Medea (2017)- realiza sobre un código antiguo (la tragedia, pero también el melodrama, el bolero, la institución familiar, entre otros) para proponer otros códigos surgidos por el empleo, el juego, con nuevos usos a fin de generar diferentes maneras de decir y reflexionar sobre el presente y pasado de América Latina.

Desde México y Costa Rica ¿con amor...?

En el año 2000, la dupla Arturo Ripstein y Paz Alicia Garciadiego escriben y filman una Medea mexicana titulada Así es la vida, volviendo sobre los pasos de Séneca pero para desviarse en los múltiples caminos que abren. En este filme los elementos estructurantes de la diégesis trágica se mantienen pero se modifican los nombres de los actantes, la condición social de sus protagonistas y el leitmotiv de las muertes de los niños. Julia (Medea), al verse traicionada y abandonada por su marido infiel, Nicolás (Jasón), y al ser expulsada por La Marrana (Creonte) de la vecindad en la cual viven, puesto que su hija se va a casar con Nicolás, decide como acto desesperado matar a sus hijos. Si en las Medeas de Séneca y Eurípides, el hecho trágico se sustenta desde el paradigma de la venganza, en este caso no es ella el motor del desenlace fatídico sino la desolación ante la dislocación espacial y afectiva que sufre esta mujer. Porque, $y$ tal como lo vemos en la primera escena del film, y ante tanta desventura que le sucede a esta Medea, que trabaja como curandera y realiza abortos, y luego de la articulación de diferentes planos secuencias que presentan al personaje principal y su medio, ella se pregunta: ¿Y yo qué? Y vos, lamentablemente nada, respondemos, porque como lo señala constantemente el coro griego desde el interior y exterior de la pantalla de televisión, ahora devenido en un trío de bolero (que en realidad son cuatro): "Si acaso te invade la tristeza. Si acaso ese que quieres, te rompió el corazón. Si acaso tú lo extrañas, y tenerlo tú quieres, venimos a decirte: no tiene solución". Más adelante, Anselmo Fuentes y sus muchachos le aclaran a esta mujer: "Tu mundo ya está muy lejos, tu mundo ya se perdió. Ahora nos queda el consejo que te damos con amor: olvida la arcadia aquella que te dio con tanto amor, ya ves que solo te queda 
angustia del corazón". Así, y ante estas sentencias (como tantas otras que le brinda el coro a lo largo del filme pero que Julia constantemente desoye) se acrecientan las profanaciones sobre las leyes de la tragedia a fin de entrecruzarse con los códigos de los medios masivos de comunicación y con el melodrama, género preferido de Ripstein y Garciadiego. En relación con este último código, nos interesa destacar aquello que Carlos Monsiváis afirma en su artículo "La política del melodrama":

\begin{abstract}
En sus versiones fílmicas, radiofónicas, televisivas, el melodrama unifica al límite la proclamación de los sentimientos, y en esa misma medida los inventa. No es lo mismo sufrir teniendo como modelos de vida a los santos y las vírgenes (que en el criterio actual cometieron el pecado freudiano de la castidad) o sufrir con el ejemplo de héroes de las novelas de folletín (...). No es lo mismo exaltarse con los monólogos de la dignidad agraviada en la recámara del abandono que exaltarse bajo la sospecha de la cámara y los iluminadores que están allí para perpetuar la elocuencia de los rasgos. Los medios electrónicos son la causa notoria de la nueva identidad social, y las personas se independizan con más felicidad del Qué dirán que de las convenciones profundas del melodrama. Al fin y al cabo la cámara escondida es el sueño de la cotidianidad (2006: 5).
\end{abstract}

En este sentido, los medios masivos y el melodrama, también profanado es sus formas clásicas, tal como lo ha observado ampliamente la crítica, funcionan en el filme de Ripstein como recursos que desactivan los procedimientos de la tragedia y permiten generar nuevos usos a fin de proponer una crítica a las lógicas del capitalismo en la sociedad mexicana.

Pero si de críticas hablamos, nos interesa concentrarnos en otro de los aspectos que el film profana y que se relaciona con la representación de la madre. Sabemos que el cine de la época de oro en México se caracterizó por la abundancia y redundancia de las madres en las pantallas, quienes se presentaron también como ejes fundamentales del melodrama. Si por un lado este cine se preocupó por la representación de la mujer equívoca, alejada de un paradigma celestial; por otro lado, se preocupó por la representación de la mujer ideal: mujeres abnegadas, inocentes, asexuadas, sufrientes, ligadas a un imaginario de lo femenino como aquellas que seden todo ante el amor de sus hijos y sus esposos. Con esta vertiente, el cine mexicano de esa época construyó una retórica en la cual la madre fue el estandarte de todos los valores morales y éticos de su sociedad. Cualquier desvío que estas mujeres pudiesen sufrir, las alejaba del paradigma ideal de la maternidad y por lo tanto la condena social era inevitable: la mujer es madre o no es nada. En su artículo "Para desbaratar a mamá", Carmelo Esterrich señala que la madre como emblema del cine de la época de oro está relacionado con un evento importante, el de la institucionalización de la madre realizada una década antes. En 
1922 se declaró el 10 de mayo como el día de la madre y para 1942 ya se establecía una semana de festejo por este acontecimiento (en la actualidad es sólo un día). Ahora bien, esta institucionalización se hace carne en el cine mexicano a partir de una actriz que se inscribió como madre y luego como abuela en la cinematografía, pero también en la televisión nacional: Sara García, la madre y abuela ejemplar. Nacida en Veracruz en 1895, debutó en el cine silente en 1917 y su carrera en cine, teatro y televisión no cesó hasta muy entrados sus ochenta años de edad. Su amplia filmografía constituye un sinfín de representaciones de mujeres (en su gran mayoría madres) que lucha por el bienestar de su descendencia y sintetiza el ideal de un buen hogar familiar. Radical en sus actos como en sus representaciones, a sus 45 años Sara García decide quitarse todos sus dientes para hacer más verosímil el personaje de anciana que debía interpretar en teatro. Con esta escisión y entrega corporal, ella sella el compromiso con su actuación como así también pone un velo sobre la experiencia trágica que le ha tocado vivir en su vida privada. Así lo señala Carlos Monsiváis en su artículo "La santa madrecita abnegada": la que amó el cine antes de conocerlo:

\begin{abstract}
En este ámbito de la maternidad como renuncia a la mentalidad independiente, Sara García, múltiple madre y abuela, es el ejemplo inconmensurable. No es mujer, ni amiga, ni ciudadana, ni profesionista, ni siquiera ama de casa; es, de manera simple y totalizadora, la Madre, ya en lo simbólico sin estructura corpórea, la de existencia vicaria, la que sólo pierde su carácter institucional si anhela vida propia. Y la actriz acepta sin problemas la cesión de derechos... (2013: 45).
\end{abstract}

Sin embargo, esta representación moralizante del cine de la época de oro, y en especial de la mano de Sara García, comenzó a presentar ciertos corrimientos: primero con Luis Buñuel en la década del 50 con filmes como Los olvidados y luego con Arturo Ripstein y Paz Alicia Garciadiego a partir de la década de los noventa con Profundo carmesí y luego con Así es la vida, entre otras. En este último caso, y con Julia/Medea como corpus y testigo, observamos que los rasgos sublimes de la maternidad son parcialmente profanados puesto que existe en ella ciertos matices que la ayudan a identificarse con esa madre ideal que la antecedió en la pantalla. Por ejemplo, en el final, cuando Julia está a punto de matar a sus hijos, trata de calmarlos y les explica por qué los tiene que matar y les dice: "lo que tiene que hacerse tiene que hacerse... ni modo. Lo que pasa es que se me acabó el mundo, se me pudrió adentro", agregando: "tu mamá te cuida siempre, ni cuenta te vas a dar", "No te va a doler, no ves que soy tu mamá". Sin embargo, estos juegos con los ideales de antaño son empleados como procedimientos de identificación pero también de crítica. Porque como afirma Esterrich: 
(...) lo que parece ocurrir, entonces, con Ripstein y Garciadiego no es la destrucción total de la imagen de familia en el melodrama, sino más bien la crítica de la distorsión creada por el cine de los años 30y 40, además del deseo de una madre mucho más compleja (y quizás por eso más desconcertante) en la tradición fílmica mexicana (2007: 13).

Así, y con esta madre que asesina primero a su hijo pequeño en el baño; luego mata a su hija delante de su padre, sentada en la escalera del vecindario y que minutos después descienda por última vez (recordamos a Aguilera Vitta quien señala que las escaleras en los melodramas dan cuenta del pasaje de un pasado funesto a un futuro prometedor), Julia huye hacia su libertad, sin la intervención de un dios ex maquina, en un carro que ya no es alado sino en un taxi marca Volkswagen que fue típico de la ciudad de México durante muchos años. Este final, acompañado del bolero que nos dice "Era historia del destino lo que a ella le ocurrió y fue también el destino que la revancha le dio", parecería dejar resonando aquello que Carlos Monsivais sentenció en su libro Misógino feminista:

En pro o en contra, ninguna abuelita de un largo período ignora a doña Sara García; hubiese sido como renunciar a un principio de identidad antes de conocerlo. Al tanto o no de sus puntos de vista, las madres de varias generaciones se modernizan o se aceptan anacrónicas por rechazar o imitar a sus correspondientes en la pantalla, bañadas en lágrimas y reproches mudos. De seguro, la primera mamá moderna no tuvo hijos (2013: 173).

Este oxímoron final (la madre que no tuvo hijos) nos permite reflexionar sobre la representación de la maternidad en Así es la vida pero también sobre la versión de Medea realizada en Costa Rica en el año 2017 por Alexandra Latishev, quien continuó con este filme representando a mujeres que escapan al estereotipo de la clase media acomodada de ese país, tal como lo hizo en sus dos cortos anteriores: L'Enfant Fatale y Sin aviso. De esta manera, la directora costarricense nos presenta una lejana y profanada Medea de Eurípides, que sólo hacia el final del filme podremos identificar con su antecesora trágica. A diferencia de Medea la hechicera, María José, la protagonista del filme, es una joven universitaria, jugadora de rugby, hija de unos padres distantes de la clase media alta de San José, amiga de Carlos con quien comparte fiestas, salidas, drogas y alcohol, y que un día se encuentra con Javier, con quien inicia una relación supuestamente "amorosa". Sin embargo, y ante esta normalidad, María José y la cámara de Latishev (a modo de metáfora para no mostrar lo que una sociedad no quiere ver) esconden un secreto: el avanzado embarazo de esta mujer. En este ocultamiento que juegan la 
protagonista y la cineasta se concentra la crítica social que la directora propone. Porque, y tal como lo afirma Latishev:

\begin{abstract}
En Costa Rica el entorno político está bastante polarizado, existen grupos fundamentalistas religiosos que están en este momento luchando en contra de la educación sexual en los colegios, el matrimonio entre personas del mismo sexo y el aborto pues ni se diga. Creo que es mi pequeño aporte en reacción a un momento histórico que estoy viviendo (2018).
\end{abstract}

Sin apelar al melodrama como lo hizo Ripstein (y a pesar de ser un género productivo en el cine de este país), profanando las tres unidades trágicas, la anagnórisis y la metabolé, el filme conserva de su intertexto trágico la idea de viaje y cambios que experimenta Medea en cada nueva geografía (de Yolcos a Corintios, de princesa e hija, a extranjera, madre, esposa y asesina) pero proponiendo una resignificación de los espacios. Esto es así porque el filme se articula a partir de micro viajes que la protagonista realiza por un recortado espacio de la capital de Costa Rica, San José, en los cuales se incluyen, por un lado, los espacios cerrados: la casa familiar, la de su novio, la de los amigos del padre, el vestuario de la cancha de rugby, el salón de una fiesta de casamiento; por otro lado, los espacios abiertos: los pasillos exteriores de la universidad, el afuera de un boliche, la cancha de rugby, el exterior de la casa de María José, estaciones de ómnibus, el parque en donde se desarrolla una fiesta de casamiento, una plaza y por último el centro de San José. Consideramos que si en los espacios cerrados María José es ignorada y deviene en un fantasma que se desliza entre cosas y personas sin provocar una reacción ante ellos; en los espacios abiertos ella se vuelve cuerpo percibido y alcanza su liberación.

Ahora bien, la representación de la invisibilidad de María José en los espacios cerrados, ya sean públicos o familiares, permite identificar la preocupación por parte del film en mostrar el lugar que ocupan las mujeres en muchas de las sociedades conservadoras latinoamericanas, el violentamiento y la invisibilización que ellas transitan puesto que "lo invisible no es, entonces, lo oculto, sino lo denegado, lo interdicto de ser visto" (Giberti y Fernández, 1989: 19). Así, la invisivilización de María José sintetiza y revela el grado de desigualdad que existe entre hombres y mujeres así como también evidencia el lugar signado para ellas en un mundo donde el patriarcado sigue operando su poderío. De tal forma lo observamos en el encuentro que se realiza en la casa de su Jasón costarricense, en el cual vemos cómo él y sus amigos no sólo no la hacen partícipe de la charla que establecen sino tampoco comparten las cervezas que toman. Este grupo de amigos, como así también sus padres y los amigos de ellos en otro encuentro que se da en otra casa familiar, ponen de manifiesto la violencia invisible que se 
ejerce sobre esta mujer. Seguimos a Evangelina Dorola quien define este tipo de violencia en estos términos:

\begin{abstract}
La violencia invisible es inherente a la constitución misma de la familia; está implícita en los roles adscriptos asignados a la mujer en razón de concepciones "naturalistas" y "esencialistas" de su condición de género, desconociendo así el carácter de construcción cultural que este reviste. Por otra parte, este tipo de violencia implícita no es fácilmente identificable, porque está legitimada desde los discursos científicos y filosóficos tradicionales, desde los discursos políticos y religiosos hegemónicos (1989: 194-196).
\end{abstract}

En detrimento de esta representación de María José en los espacios cerrados, observamos cómo ella vive su vida, goza y desea en los espacios abiertos, cobrando de esta manera una materialidad y una voz. Aun en el caso de que esa presencia devenga en accidente o tragedia, como es el caso de la escena en la cual en el exterior de una fiesta es atropellada por un auto o, hacia el final del film, en el exterior de su casa, su cuerpo de desliza para esconder los restos de su acto radical. Sin embargo, un solo espacio cerrado es aquel que nos permitirá conocer en profundidad a María José, su baño y su espejo en el cual se refleja, a través de planos medios y americanos, el incipiente embarazo de la protagonista y su desenlace: el infanticidio, al cual accedemos mediante un plano medio que muestra el rostro sufriente de la protagonista y que se acentúa con sus gemidos y llantos ante tanto dolor de parto en el inodoro de ese baño. Así, en este espacio accedemos al conflicto que atraviesa a María José, un embarazo no deseado y su resolución. Sin embargo, la cámara se ubica como un testigo que no pretende generar una crítica sobre esta mujer sino que por el contrario, nos desnuda su cuerpo y mente a fin de que se genere el más alto grado de empatía con la protagonista. Como en Así es la vida de Ripstein, y en especial en la escena en la que Julia mata a su hijo en el baño, los espejos nos ubican en ese lugar que no deseamos mirar pero que en su refracción o reflejo nos enfrenta con nosotros mismos y con nuestros fantasmas sociales. Así concebidos, los espejos de estos dos filmes nos proporcionan las palabras que estas mujeres callan y nos sintetizan la solución de sus conflictos, que a pesar de su resolución no dejan de tener el peso de su tragicidad.

Cabe destacar la acertada y precisa actuación de la protagonista de Medea, Liliana Biamonte que, respondiendo a la idea de negación del cuerpo como lugar de dominio del otro en sociedades patriarcales, se impone mediante los silencios y la relegación del gesto a fin de provocar su extrañamiento. Asimismo nos presenta un cuerpo rígido que pareciera querer investir a quien se le cruce, que evita el desparpajo y acentúa su planificación, descartando la 
afectación, en los traslados geográficos que ella realiza. Todo ello para crear un personaje, que en palabras de la propia actriz, "actúa más que reflexiona y que se niega a tener conciencia de lo que le está pasando y de la transformación física de lo que está viviendo" (2018). Una actuación que se contrapone con la de su colega, Arcelia Ramírez en Así es la vida, que se sustentó en la exaltación de la palabra, en la alternancia de los tonos del llanto y el desafío y sobre todo, en la evidenciación de un cuerpo sufriente y más cercano a un cuerpo grotesco, en el sentido que Le Breton (2015) le da a este término, como aquél que se encuentra inacabado, provisorio y que siempre se encuentra en transfiguración.

Retomando la idea de vertebración de ese único espacio privado por excelencia con los recorridos que señalamos previamente, encontramos que en ese peregrinaje María José deviene en no madre (o en la madre moderna que no tuvo hijos, como señalaba Monsiváis), y en ese oxímoron consolida su identidad, adquiere la soberanía sobre su cuerpo y se opone a los paradigmas sociales conservadores de la sociedad costarricense. Nuevamente en ese espacio, y casi hacia el final del film, la escena de María José bañándose, y luego de haberse rapado el pelo, clausura el relato sobre la no maternidad a través de una imagen afección, que acompañada de los colores fríos y por momentos en blanco y negro que caracterizan al film, sintetiza la propuesta estética e ideológica de Latishev (Ulate, 14/12/2017): "pues evita recurrir a elementos como el guión, por ejemplo, como principal medio para manifestar el encarcelamiento psicológico al que se somete el personaje". Por ello, el cuerpo de la actriz se vuelve el territorio más nítido y productivo para la directora costarricense, porque es la materialidad del cambio indiscutido y que no se puede negar. Así lo explica la directora:

\begin{abstract}
Creo que asumí el reto de contar desde el cuerpo, y eso involucra textualmente contar sobre el entorno desde la corporalidad del personaje. Cómo reacciona, cómo actúa en relación con ese entorno, también reafirma esa idea de negación. De alguna manera, nadie da la cara, solo el personaje. Eso genera más tensión sobre el espectador que es casi que el único en enterarse de lo que vive (Díaz Zeledón, 3/5/2018).
\end{abstract}

Por último, y como Julia de Así es la vida, María José se lanza al espacio de la ciudad, dejando atrás aquello que no se desea y ganado su cuerpo y su deseo como patrimonios innegociables. Quizá, Julia podría haber acompañado a María José en su decisión de no ser madre desde su laboratorio; quizá podrían haber compartido sus penares entre chelas y coca colas; quizás, quizás, quizá. Pero lo concreto es que la Medea costarricense, entre las sombras y el fuera de campo, entre el silencio y los gemidos de dolor de parto, concreta su deseo. De esta manera, y sólo dejando el nombre de la heroína trágica, Medea, como símbolo de libertad, el universo de 
este filme se propone como un grito ante un entorno social y político que silencia a la mujer y desoye el reclamo que atraviesa a gran parte de las sociedades latinoamericanas en la actualidad y que puede sintetizase con el lema: "Educación sexual para decidir, Anticonceptivos para no abortar y Aborto legal para no morir." $Y$ que esperamos que más temprano que tarde, sea ley. Porque en un país, como en tantos otros latinoamericanos, en donde el aborto es penalizado y el aborto terapéutico es casi una utopía (aun en casos claros en los cuales corre alto riesgo la vida de la mujer), la necesidad de un cambio social, político y religioso se vuelve necesaria e inminente. Así lo afirma María José Cascante:

\begin{abstract}
Además, en el contexto actual centroamericano y con una mayoría conservadora en la Asamblea Legislativa, de aprobarse el proyecto de ley heredado por Fabricio Alvarado para equiparar las penas de aborto con las de homicidio, se abre un portillo que pone en riesgo el artículo 121 del Código Penal y que pueden dejarnos más cerca a lo que sucede en El Salvador y Nicaragua donde existe una prohibición total del aborto que lleva a la cárcel a las mujeres más pobres que han sufrido abortos espontáneos (08/2018).
\end{abstract}

\title{
Conclusión
}

Monserrat Sagot afirma que hay tres factores los que fueron asociados con la violencia en el mundo:

a) Normas sociales que justifican en los hombres un sentido de posesión sobre las mujeres.

b) Control por parte de los hombres de los recursos materiales y de la toma de decisiones en la familia. c) Concepciones culturales de masculinidad asociadas al control, el dominio y el honor (2008: 217).

En los dos filmes aquí analizados, y considerando la diferencia estéticas y estilísticas que han elegido para el tratamiento de sus historias, observamos que estos tres factores se hacen presentes y se sintetizan sobre los cuerpos de dos mujeres: Julia y María José. Además, mediante la profanación del silencio que ha caracterizado el lugar de inscripción de las mujeres, estos dos filmes instauran su lucha y promulgan por la necesidad de salvar otros cuerpos similares antes de que caigan al otro lado del precipicio.

Así también, nos interesa destacar que ambos filmes coinciden en problematizar sobre la maternidad en las sociedades contemporáneas y sobre el poder de decisión que tenemos las mujeres sobre nuestros cuerpos y nuestros deseos. Si bien las claves trágicas profanadas que 
eligen las dos películas establecen una puerta de salida a la opresión que sí o sí conllevan el peso de la crítica e impugnación social, los directores no condenan ni castigan a estas mujeres sino que muestran, hacia el final, un atisbo de su poderío. En el caso del film Medea la problemática se concentra en la elección de no ser madre en una sociedad en la cual el aborto no es una opción alcanzable. Mediante la negación de su embarazo por parte de la protagonista y la acentuación de este ocultamiento por medio de una cámara que privilegia los primeros planos y los medios se evidencia la ruptura con un paradigma que durante años y años a estigmatizado a la mujer: su naturaleza es la de ser madre. En este sentido, el film de Latishev recupera la perspectiva teórica que desde la psicología y los estudios culturales y antropológicos se establecieron desde hace tiempo: la maternidad es una construcción cultural y por lo tanto la posibilidad de elección debe ser una alternativa válida e incuestionable. Por último, tanto Así es la vida como Medea abogan por la ruptura con la sujeción del cuerpo y el deseo al mandato y deseo del otro y en esa ruptura abren las posibilidades para pensar y reposicionar estos cuerpos femeninos (y los nuestros) en la larga historia de los cuerpos femeninos silenciados por la historia y que aún hoy continúan siendo acallados.

\section{Bibliografía}

Agamben, G. (2013). Profanaciones. Buenos Aires: Adriana Hidalgo Ediciones.

Aguilera Vita, A. (2017). Arturo Ripstein, un cine entre tragedia griega y naturalismo. Procesos Históricos. Revista de Historia y Ciencias Sociales, 31, enero-junio, 2017, pp. 107-122.

Aguilera Vita, A. (2011). Las Dos Medeas de Ripstein. Revista metakinema. Recuperado de https://bit.ly/2HTDOyJ

Cascante, M. J. (8/2018). Por qué se habla ahora del aborto en Costa Rica. Recuperado de https://semanariouniversidad.com/opinion/por-que-se-habla-ahora-del-aborto-en-costarical

Díaz Zeledón, N. (3/5/2018). Llega Medea a los cines: una mujer secuestrada. La Nación. Recuperado de https://bit.ly/2kq9V68

Dorola, E. (1989). La naturalización de los roles y la violencia invisible. En La mujer y la violencia invisible. Buenos Aires: Sudamericana.

Esterrich, C. (2007). Para desbaratar a mamá: el último cine de Arturo Ripstein y Paz Alicia Garciadiego. Recuperado de http://www.historiadeltraje.com.ar/hamal/pdf/mexico/paradesbaratar-a-mama.pdf 
Giberti, E. y Fernández, A. M. (1996). Introducción. En La mujer y la violencia invisible. Buenos Aires: Sudamericana.

Le Bretón, D. (2002). Antropología del cuerpo y modernidad. Buenos Aires: Nueva Visión.

López Aranda, S. (1996). Arturo Ripstein: la construcción sin fin. Nosferatu. Revista de cine, 22, pp. 4-9.

Monsivais, C. (2006). La política del melodrama. Recuperado de www.panoramadelarte.com.ar/hamal/pdf/la politica del melodrama.pdf

Monsivais, C. (2013). Misógino feminista. México: Océano.

Paranaguá, P. A. (1996). Ripstein y el melodrama: a través del espejo. Nosferatu. Revista de cine, 22, pp. 10-13. Recuperado de https://bit.ly/2IQZVmP

Rinsesi, E. (2015). Notas sobre la tragedia y el mundo de los hombres. Revista Anacronismo e Irrupción, 5(8), pp. 271-296.

Rodríguez, A. (17/2/2017). 'Medea', una mirada crítica a la Costa Rica ultraconservadora. El país.

https://elpais.com/cultura/2018/02/16/actualidad/1518739330 073430.html

Sagot, M. (2008). Estrategias para enfrentar la violencia contra las mujeres: reflexiones feministas desde América Latina. Athenea Digital, 14, pp. 215-228. Recuperado de http://psicologiasocial.uab.es/athenea/index.php/atheneaDigital/article/view/571

Ulate, E. (14/12/2017). Reseña de Medea (2017) de Latishev. Recuperado de http://contexto.cr/pinata/cine/2017/12/14/resena-medea-2017-alexandra-latishev/ 